\title{
BEAUTY CONCEPT \\ REPRESENTED ON COSMETIC ADVERTISEMENT
}

\author{
Diana Rahmawati \\ Suryakancana University \\ dianarahmawati2@gmail.com
}

\begin{abstract}
The issues surrounding beauty concepts such as related to women in color, how society make their own standard of beauty and how its prevalence in any mass media's advertisements deserve our attention. Fenty Beauty tried to handle those problems related to skin tone and beauty standards. The objectives of this research were to analyze how the cosmetic advertisement represent beauty concepts according to semiotics signs, and to decipher messages conveyed by verbal (tagline) and visual signs in cosmetic advertisement represent beauty concept. The participants of this research are Rihanna and eleven models in Fenty Beauty advertisement video in each scenes. The Fenty Beauty video itself captured woman with different skin tones, hair, body sizes, ethnicity and religion. To obtain the data the researcher used two instruments namely video observation, and documents analysis. The findings investigating the beauty concepts cover the skin tones, make up, hair and face symmetry. Meanwhile, the finding examining messages there verbal and visual sign. Verbal sign was found in two types. The first is 'the new generation of beauty'. It means as freedom of expression in creating beauty looks based on their apparences. The second is 'Fenty Beauty by Rihanna', it means beauty is something personality. The messages are conveyed in visual signs are everyone is beautiful in their own way with what is God already given. There's no concrete standard for beauty relate to skintone, hairs and face symmetry. The natural make up always makes someone more gorgeous. Furthermore, the researcher would also suggest further research to incorporate readers to think critically and open-minded what they see in cosmetic advertisement.
\end{abstract}

Keyterms: Beauty concepts, cosmetic, advertisement, semiotics.

\section{INTRODUCTION}


The United State is often described as a "melting pot" or a "salad bowl" of different ethnicities and cultures. With so many different groups and people, one may expect a plethora of definitions about beauty. The Ideas about physical beauty concepts are likely to permeate some societies, however more pressure seems to be put on women to be attractive than a man because women are often judged more on their looks than on any other personal aspects or qualities. Beauty is a construct that varies from culture to culture and changes over time and women try to reach this standard of beauty and they often times fail because for many, it is an unrealistic and unattainable desire.

Started from those phenomena, finally the researcher concluded this study should be done. The reason is to prove if the beauty concepts exist through society and the media has a role in it. And to show how the media (advertisement) convinces the customers to buy the products because there's a problem that many people look at cosmetic advertisements and buy things under its influence. Why this brand makeup is chosen, because Fenty Beauty has tried to handle those problems related to skin tone and beauty standards. However, not only is this western ideal of beauty (especially in U.S.) emulated by white women, it is also becoming a desired beauty standard for many minority women as well. The researcher has long harbored an ambition to make a contribution to spreading body positivity among people, especially black people that always have a negative image in any mass media's advertisements.

\section{THEORETICAL FOUNDATION}

\section{Definition of Beauty}

Originated from the Old French word beauté, which means "physical attractiveness, goodness, and courtesy" (Franklin, 2010). Many techniques for the aesthetic enhancement of one's physical appearance, the most obvious one is the use of cosmetics. Attractive people are considered to have more positive interpersonal attributes, such as intelligence, happiness, and extroversion (Dion, 1972). Most of characteristic of woman physical appearance is promote elusive beautiful image to women of all ages, shapes, and sizes which are sometimes, do not fit with the reality occurs in daily life. Fenty Beauty's advertisement is chosen because the makeup line with models of different skin tones, religions, and backgrounds showing that all can be beautiful. 
As Vacker (1993) points out, beauty as an axiom can be classified into subjective and objective. Subjective beauty derives from the subject's mind and the ideal is created from feelings, emotions or person's judgments due to increased necessity of choice. Another perspective, objective beauty, is acquired through the external reality and a beautiful object is formed independently of the mind's substantiation of beauty or is even non-existent in our world and therefore only possible to experience through certain objects which beautiful is channelled through.

\section{Cosmetic Advertisement}

Williamson (1978) analyzed advertisement. He argues that, advertising presents a mirror image that gives false hope towards the imaginary unity of the Ego-Ideal. Cosmetic is known as makeup or make-up, are beautifulness product made from substances that used to enhance the appearance or odor of the human body and make them more beautiful and comfortable with their look to shows in public. On of cosmetic brands in U.S. is Fenty Beauty, and the founder of is Rihanna. The brand focused on the issue of black women and skin tone in the U.S.

\section{Semiotics}

The term semiosis (or semeiosis) and defined it to mean an "action, or influence, which is, or involves, a cooperation of three subjects, such as a sign, its object, and its interpretant, this trirelative influence not being in any way resolvable into actions between pairs" (Peirce, 1860). Another statement semiotics is closely related to the field of linguistics, which, for its part, studies the structure and meaning of language more specifically. The Semiotic tradition explores the study of signs and symbols as a significant part of communications. Saussure illustrates that a sign consist of signifier and signified. Those two elements as like two sides of a coin that cannot be separated, (Saussure, 1983).

\section{The Signs of Beauty Concept consist of Skintone,}

Hunter (1998) believes skin tone is often perceived as a form of fixed or unchangeable capital which individuals attempt lighten or darken to enable them to be accepted as desirable or part of the in-crowd where one worth is judged based their appearance. Hair, Thompson (2009) explains, hair has a unique ability to "function as a key ethnic signifier because compared with bodily shape or facial features, it can be 
changed more easily by cultural practices such as straightening. Make up, the effects of makeup on attractiveness have been evaluated using mainly subjective measures. According to recent scientific research, symmetry represents the concept of proportionality. Measures of symmetry in the human body and face correlate with attractiveness (Enquist, 1994).

\section{RESEARCH METHODOLOGY}

The researcher used descriptive qualitative, it means this research give explanation clearly about understanding in relation to the observation and documents analysis. Creswell (2013), adds qualitative research is an inquiry process of understanding based on distinct methodological tradition of inquiry that explores a social human problem.

This study site in cosmetic advertisement video of Fenty Beauty by Rihanna from www.fentybeauty.com and www.youtube.com which was launched on September 7, 2017 at Sephora Times Square, New York. The participants of this research are Rihanna and other eleven people that appear in every each of scenes of Fenty Beauty advertisement video. The brand used the images of various models with different ethnicity like African American, Latinos, and Asian women to associate Americans with a global cosmetic.

Arikunto (2006) states that data are everything that taken from observation wheather they are facts or numerical sources. the researcher used document analyzing of the cosmetic advertisement video that represents beauty concepts. The researcher has the steps as follow: First, the researcher downloads an official video of Fenty Beauty: Shades For All advertisement from www.fentybeauty.com and www.youtube.com. Second, the researcher watches and listens to the video. Third, the researcher takes a note and capture each part of scenes when the models appeared in the Fenty Beauty: Shades For All. Then, the researcher identifies the messages that are conveyed and coding beauty concepts in four aspects using semiotics sign. The types of semiotics signs consist of signs/representemen, object and interpretant. Document analysis is a form of qualitative research in which documents are interpreted by the researcher to give voice and meaning around an assessment topic (Bowen, 2009).

\section{Data Analysis}

The method of analyzing data which was used by the researcher were first analyzed the tagline of advertisement by listening to the videos and watching it then took a capture 
of the data to get deeper understanding. Second In this analysis, the researcher categorized the beauty concepts on models appearances (skin tone, face, hair, and makeup) used the semiotics sign consist of signs (representamen), object and interpretant. The researcher discussed and explained the type of meaning and the interpretation that has been found one by one to answer the research questions. The last step was drawing the conclusion and the suggestion.

\section{FINDING AND DISCUSSION}

This chapter presents the finding and the discussion of beauty concept represented on cosmetic advertisement. Furthermore, discusses how the cosmetic advertisements represent beauty concept according to semiotics sign and to find out messages that are conveyed by verbal (tagline) and visual sign.

\section{The Cosmetic Advertisements Represent Beauty Concept According to Semiotics Signs.}

Referring to the evidences, the findings show that twelve models appeared on the video have a different ethnicity, skin tone, hair and make up. It make them more beautiful. The beauty concept consists of several aspects such as; skin tone, make up, facial symmetry, and hairs, each of them presented in cosmetic advertisement Fenty Beauty were analyzed by using the theory proposed by Pierce (1860) which is a cooperation of three subjects, namely a sign/representamen, object, and interpretant.

\section{Skin tone}

The beauty concept defines here is that beauty is for every woman, and for every skin tone. Women in the 2000s have been bombarded with so many different requirements of attractiveness. In the video the models strongly biased the results as people do find clear skin attractive.There are stereotyped having a lighter skin is evidently tied to the idea of being more beautiful (Thompson, 2009) but it doesn't appear here. They become beautiful women with not constrained by the stereotypes. There as a hopeful message of "Don't be ashamed of your desire for beauty," as well as the old message of beauty a duty" (Hill, 2002).

\section{Make up}

The models applied make up to be look like Rihanna, knew as "RiRi looks" concept nude, natural shading and contouring to give more defined, plump lips and glowing. The 
natural make up always suitable for any skin tone from the darkest to lightest. The slightest bit of makeup can help create a more perfected version of someone. Cash, (1982) state women wear makeup to increase other people's perceptions of their likeability, competence, and trustworthiness.

\section{Face Symmetry}

Measures of symmetry in the human body and face correlate with attractiveness (Enquist, 1994). From the website, the researcher can measure the facial symmetry of each model who appeared in the video, because the facial symmetry usually has an algorithm. The score is almost too perfect, their faces are completely symmetry from side to side. There literally is a mathematical standard for what's "beautiful" that conditioned at a genetic level to be predisposed to find attractive. People who are closer to that standard with minimal deviation from it look good for another while people who are substantially far off the mark tend to be unattractive.

\section{Hair}

The beauty concept were presented on cosmetic advertisement there are the women who have various hair textures, length, colors and styles. Women with hijab focus on inner beauty not outer beauty. The models look stylish without too much style on their hair, simplicity and tidiness on the point. The hair is helping to indicate someone's ethnicity and personality. As Thompson (2009) explains, hair has a unique ability to "function as a key ethnic signifier because, compared with bodily shape or facial features, it can be changed more easily by cultural practices such as straightening".

\section{The Messages are Conveyed by Verbal (Tagline) and Visual Signs in Cosmetic Advertisement Represent Beauty Concepts.}

The messages are conveyed by verbal (tagline) analyzed based on the theory of signifier and signified by Saussure. The messages are conveyed by visual sign analyzed based on the theory of sign/representamen, object, and interpretant by Pierce, it explains in detail below.

\section{Verbal}

There two tagline were appeared in the video of cosmetic advertisement.

First, "Fenty Beauty by Rihanna", the message is Fenty Beauty wants women to make their own perspective of beauty that does not allow standard of the society that usually forced them to follow without knew the potential of their beauty because each person are 
different. Second, “The New Generation of Beauty” the message is there isn't boundary of beauty whether it is skin tone, ages, size, culture and ethnicity, religions is included. The new generation of beauty is also means as freedom of expression in creating beauty looks based on their appearances.

\section{Visual}

The visual signs of beauty concepts divided into four aspects; skin tone, make-up, facial symmetry, and hairs, it has been analyzed using Pierce's theory which are sign/representamen, object, and interpretant.

\section{Skin tone}

That beauty concept which related to skin tone are, every skin tone has attractiveness and beautiful. Besides concern with outer beauty, inner beauty is important too, such as the way the model showing her beauty with confidence. When someone has a high self-esteem, it means she loves herself, and showing her inner beauty. Maintain healthy skin to always look healthy and pretty.

\section{Make up}

Beauty isn't always about heavy make up with full coverage, the fact that light makeup that enhances natural facial expressions is often considered attractive or appropriate in daily situations. The slightest bit of make up can help create a more perfected version of someone.

\section{Face symmetry}

The beauty that have proportional ratio, that each side are the same but there literally is a mathematical standard for what's "beautiful" that conditioned at a genetic level to be predisposed to find attractive. Not all the models got perfect number in their facial features, but perfect in last accumulation score, for human there advantages and disadvantages.

\section{Hair}

The researcher thinks the majority of black women do not change their hair, even black women who use perms because is an identity of their ethnicity. For black women who already styled their hair because they want to "look white," it is totally wrong, black women do these things because their hair can be. No matter what is your hair color and hair styles or wearing hijab you always have to show the inner beauty and have a healthy hair. 


\section{CONCLUSION AND SUGGESTION}

\section{Conclusion}

The beauty concepts that found in cosmetic advertisement the first is various skin tones, which are dark, tan, medium, and light they have a healthy skin look glowing, smooth, flawless and high moisturized. The models represented 'Women in color' that have equality of beauty no matter what are their ethnicities. The second is make up, the models applied make up look like Rihanna, knew as "RiRi looks" concept nude, natural shading and contouring to give more defined, plump lips and glowing. Beauty as Rihana with natural looks and it suitable in any skin tones. The third is hair, the beauty concept, here are the women who have various hair textures, length, colors and styles. The last is facial symmetry, that symmetric faces are considered more attractive and healthy, most pf the models showed that beauty concept related to their facial symmetry consists of the width of the base of the nose is approximately equal to the distance between the eyes, the forehead is the same length as the nose. The eyes are also perfectly positioned and spaced apart.

The messages are conveyed in verbal and visual sign. Verbal sign was found in two types. The first is 'the new generation of beauty. It means as freedom of expression in creating beauty looks based on their appearances. The second is 'Fenty Beauty by Rihanna'. It means beauty is something personality. The messages conveyed in visual signs were everyone is beautiful in their own way with what is God already given. There's no concrete standard for beauty relate to skin tone and hairs. The natural make up always makes someone more gorgeous.

\section{Suggestion}

The influence of cosmetic advertisement is a huge aspect to consider because it can manipulate people easily in different range of ages about beauty concept. And so that, all founders of brand make up have to concern portraying the beauty concept between white and black people. The advertisement has to relevant with the reality, do not make unrealistic beauty that people hard to achieve and the impact can make people blaming themselves for being ugly.

Furthermore, the researcher would also suggest further research to incorporate audience to think critically and open-minded what they see in cosmetic advertisement. 
This research is also expected to motivate future readers and researchers have a better understanding about how semiotics analysis can influence us in many aspects in addition present us, as the audience, the entertainment that we need.

\section{REFERENCES}

Arikunto, S. (2002). Prosedur Penelitian (Suatu Pendekatan Praktik): PT. Rineka Cipta.

Bowen, Glenn A. (2009), 'Document Analysis as as a Qualitative Research. London and New York: Routledge.

Cash, T.F., \& Cash, D. W. (1982). Women's use of cosmetics. Psychosocial correlates and consequences. International Journal of Cosmetic Science.

Dion, K. BerscheicL E. \& Walter, E. (1972) What is beautiful is good. Journal of Personality and Social Psychology.

Enquist, M., \& Arak, A. (1994). Symmetry, beauty and evolution. Journal of Beauty.

Franklin Electronics Publishers, I. (2010). Oxford Dictionary: Franklin Electronics Publishers, Incorporated.

Hill, M. E. (2002). Skin color and the perception of attractiveness among African Americans: Does gender make a difference?. Social Psychology Quarterly.

Hunter, M. L. (1998). Colorstruck: Skin color stratification in the lives of African American women. Sociological Inquiry.

Pierce, C.S. (1860). Philosophical writings of Peirce. J. Buchler (Ed.), 
New York: Dover Publications.

Author: Diana Rahmawati

Vacker, B. (1993). Beauty and the Beast (of Advertising). Advances in Consumer

Research.

Williamson, Judith (1978), Decoding Advertisements; Ideology and Meaning in Advertising. London: Marion Boyars. 